\title{
Development of Novel High-quality Educational Resources
}

\author{
Gang Ding ${ }^{1, a}$ and Dan-yang Cao ${ }^{2, b}$ \\ ${ }^{1}$ Office of Academic Affairs, Harbin Institute of Technology, China \\ ${ }^{2}$ College of Mechanical and Electrical Engineering, Harbin Institute of Technology, China \\ adingganghit@163.com, bjonacao@yeah.net
}

Keywords: development of MOOC, teaching of universities, equality of Chinese education, national education sovereignty.

\begin{abstract}
Massive Online Open Courses, abbreviated to MOOC, have attracted extensive attention from education circle, especially the circle of higher education, immediately after their emergence. Students, teachers, schools, government and even the whole society are eager for seeing what changes MOOC will bring to Chinese education that remains to be urgently reformed.

First of all, development of MOOC and conventional courses is comparatively analyzed in this paper. Next, high-quality educational resources are illustrated to be developed based on MOOC for solving main problems and challenges concerning teaching of universities, equality of Chinese education and national education sovereignty, in order to put forward opinions and suggestions for improving teaching practices inside universities, offering satisfactory education to people and safeguarding national educational sovereignty.
\end{abstract}

\section{Introduction}

In April 2003, the Notice of the Ministry of Education on Developing Exquisite Engineering Courses for Teaching Improvement and Reform of Universities (No.1 Document issued in 2003) was issued, which signified that it had been a peak period for developing conventional courses in Chinese universities.

\section{A Comparative Analysis on Development of MOOC and Conventional Courses}

Generally, conventional courses are developed out of step with dynamically changing classroom teaching. Classes act as bridge and tie that closely integrate teachers, students and courses[1]. Advanced educational philosophies, teaching methods, content and design, etc shall not be separated from classes. Adequate importance is supposed to be attached to classroom teaching, or else talent cultivation will be negatively impacted.

To further strengthen improvement of classroom teaching in the process of course development, the Ministry of Education issued the Opinions on Developing National Exquisite Open Courses (No.8 Document issued in 2011) in December 2011 to initiate the development of national exquisite courses for resource sharing. In a new round of course development, an emphasis was laid on recording the whole process of classroom teaching by videos. To a great extent, this solved the universal problem that development of conventional courses was isolated from classroom teaching [2]. However, new problems emerged in that process. For instance, records were made for all courses according to number of classes. Each class lasted approximately 45 to 50 minutes, recorded with a memory up to more than $1 \mathrm{G}$. Thus, almost tens of gigabytes were necessary for a course. In this case, it was unfavorable for spreading and using course videos. As a result, excellent strategic visions of the Ministry were far below expectations.

Meanwhile, MIT and Harvard University respectively invested thirty million US dollars in building the first platform of MOOC known as edX all over the world [3]. Based on this platform, massive online open courses were developed and opened. China even launched such courses earlier than MIT and Harvard University. However, it achieved completely different effects in these courses from the later MOOC launched by above two universities mainly because of following reasons as follows: 
1. In MIT, MOOC and pertinent platform have been developed by considering universities as subjects, so the development belongs to a bottom-up conscious act. Nevertheless, "national exquisite courses" and "national exquisite open courses" have been developed according to top-down administrative requirements of the Ministry of Education in China, to guide teachers to highlight course declaration without regard to course development or quality, so the course development isn't active.

2. Massive Online Open Courses have been developed on the premise of fully considering learners' abilities to acquire new knowledge. Education and teaching concepts have been thoroughly transformed. Subsequently, objectives have been realized by various means via information technologies, in order that learners' study isn't limited by time and space. Besides, attention has been especially paid to make up deficiencies of previous course videos in interactions/exchanges between teachers and students and online tests. In this way, "class replay" has been perfectly transformed into "ideal class representation".

3. Platform of MOOC has been built based on latest achievements in information technologies, such as cloud computing, mobile internet, artificial intelligence and big data analysis, so as to provide more considerate services for learners in terms of dissemination and application of course resources.

4. Integrated with flipped classroom teaching, MOOC may even achieve teaching effects not lower than those of traditional face-to-face classroom teaching. In this way, valuable opportunities will be provided for universities lacking relevant education and teaching resources to expand and develop themselves. At last, it is inevitable that an educational revolution will be initiated.

After their emergence, Massive Online Open Courses have aroused wide concern of Chinese circle of education, particularly higher education. In addition, the Ministry of Education issued the Opinions on Strengthening Development, Application and Management of Online Open Courses in Universities (No. 3 Document issued in 2015), in order to guide and standardize orderly development and implementation of MOOC in a top-down manner. Original "post-review development" has been changed into "pre-review development".

Better effects will be definitely achieved as long as Massive Online Open Courses are developed in combination with bottom-up and top-down methods. For instance, with the support from the Ministry of Education in policies concerning credit recognition, perhaps Chinese universities face smaller difficulties than foreign universities. Therefore, attempts may be made to discuss how to solve striking problems and conflicts related to teaching of Chinese universities, equality of domestic education and national educational sovereignty by system of MOOC.

\section{Solving Main Problems with Teaching of Universities Based on MOOC}

In China, teaching of universities, particularly undergraduate teaching, mainly has two problems as follows.

Firstly, students aren't highly concentrated on their study, mainly because they have adapted to examination-oriented education so much that their creativity and enthusiasm about study have been extinguished by such education. Additionally, some teachers are too lazy to adjust or update content of courses in spite of opportunities available to them due to their lack of responsibilities and initiatives. Classroom teaching methods and means aren' $t$ diversified, but simply focus on teachers' impartment. Besides, evaluation methods are so unvaried that students pay too much attention to their scores. As a consequence, it is impossible for students to develop their innovative thinking and creativity as possible as they can. Although a reform has been carried out in the Harbin Institute of Technology to assess students mainly by cumulative evaluations over the past years, some teachers have still failed to change their education concepts of simply and formalistically meeting requirements of universities, thereby negatively affecting talent cultivation. In view of aforementioned perspectives, it may be discovered that students haven' t concentrated on their studies, mainly because teachers haven' t really assumed their responsibilities for developing virtues, fostering talents, imparting knowledge and educating students. Therefore, the other problem is supposed to be teachers' failure to devote to teaching. Motivated by titles and financial benefits, 
teachers generally highlight scientific research, but neglect teaching. It is even impossible for teachers who attach importance to teaching to voice their opinions. Or no importance will be attached to their opinions even if they deliver them. Then, to firmly establish central position of talent cultivation in school work has become a preferred empty talk that has been never put into practice for all presidents of universities.

Students will be the most potential victims if it is impossible to establish central position of talent cultivation and attach due importance to teaching. As a well-known educator, John Dewey said that students would be deprived of their tomorrow as long as they were taught by methods of yesterday [4]. Apparently, schools are fundamental causes of that problem. In case of no changes to schools' criteria for evaluation and appointment, teachers will be not concentrated, responsible and conscientious in teaching all the time.

Then, can these problems be solved by MOOC? Hereunder, an introduction is made to discuss if Massive Online Open Courses are taken seriously or not.

Perhaps, it may be said that, it is critically important for students to actively learn all open courses on the platform of MOOC to become talents by themselves if such courses aren' $t$ treated seriously by schools. Impacted by environment, students have been possibly adaptable to passively receive low-quality education of schools. Hence, research needs to be further conducted to know and confirm the number of students who are active in taking MOOC.

Compared with others, schools where Massive Online Open Courses are taken pay more attention to their course development, undergraduate teaching and talent development. Nevertheless, it is difficult to get rid of past malpractices owing to conflicts between scientific research and teaching. Hence, some difficulties will be encountered in ensuring quality of talent cultivation. However, it is possibly helpful for solving these problems by making appropriate use of MOOC. For example, perhaps some schools have prominent advantages in their engineering specialties, but great weaknesses in their courses of general education. Schools may introduce plenty of high-quality MOOC from pertinent platform to improve their general education. Except that numerous high-quality MOOC resources may be introduced, schools also need to support and encourage teachers who are enthusiastic about teaching to develop MOOC, in order that teaching philosophies, teaching methods and content of courses can be synchronously reformed and innovated. This may not only improve talent cultivation, but may also appropriately resolve conflicts between scientific research and teaching.

After the emergence of MOOC, students-centered education and teaching concepts have been really developed, driven by students' academic performances. They may make talent cultivation models innovative. It is thus clear that Chinese universities' remarkable problems and major conflicts about undergraduate teaching and talent cultivation may be well solved by MOOC. It is noteworthy that in the process of MOOC development, it is necessary to synchronously reform and innovate teaching concepts, teaching methods and content of courses pursuant to practical needs of teachers and students for the final purpose of improving teaching. In the mean time, hardware and software construction, organization and policies shall be guaranteed.

\section{Solving Main Problems about Equality of Chinese Education Based on MOOC}

At present, inequality is a major problem of education in China, which is primarily reflected and results from lack of high-quality educational resources, uneven distribution and unbalanced allocation of resources.

Perhaps, lack of high-quality educational resources doesn't need to be deeply explained here, as it may be completely known from China's gaps with Europe, America and even Japan on rankings of different universities. Macroscopically, high-quality educational resources are mostly centralized in large/medium-sized cities and developed provinces in China. Concerning unbalanced allocation of high-quality educational resources, from a microscopic perspective, such phenomena may even exist among streets of a city and towns of a county. Under this circumstance, lots of "talents" with great skills in passing examinations but poor practical skills have been fostered by inherently scarce 
educational resources. In this case, it is extremely unfavorable for Chinese government to implement strategies concerning "mass entrepreneurship and innovation".

Then, how to expand high-quality educational resources to ensure educational equality? It is feasible to facilitate dissemination of high-quality educational resources while expanding pertinent approaches. Through such dissemination, finite high-quality educational resources may be utilized to the largest extent within limited time. The ways and speed for resource dissemination are closely associated with sciences and technologies of the society where the resources are.

Education has constantly developed with the progress of human civilization and presented distinct characteristics in each era. Nowadays, information is collected and disseminated at an unprecedented speed and scale thanks to rapid development of information and network technologies. Thus, information can be shared and exchanged all over the world. In addition, current education has been tremendously impacted by information and network technologies. Making static knowledge dynamic, multimedia courseware hasn't only improved classroom teaching and its efficiency, but also made dissemination easier with the aids of USB flash drive and internet. It has saved dissemination costs, greatly expanded dissemination and increased gains of educational resources. Teaching and learning based on multimedia courseware may be considered as another major reform of human education after the emergence of movable type printing for nearly 1, 000 years.

Within 100 years after this reform, MOOC will further greatly promote educational innovation of human beings. The great success in MOOC is inseparable from maturity of current information technologies like mobile internet and popularity of mobile terminals. With the emergence of MOOC, knowledge and cultures may be transmitted without any limits of time and space. Based on MOOC, high-quality educational resources may be disseminated faster and more widely. In the future, high-quality educational resources of Tsinghua University will cover hundreds or tens of thousands of students by rapidly spreading MOOC. In this way, on one hand, relatively prominent problems regarding educational equality will be solved; on the other hand, more outstanding innovative talents urgently demanded by the country will be cultivated.

Based on above discussions, let's see how to solve prominent problems with Chinese education via MOOC. Assuming that educational system and mechanism are bottles, educational resources are supposed to be wine. At first, quality of wine shall be guaranteed. Next, the bottles shall be beautiful, endurable and easy to use. Only in this case will a bottle of wine be attractive. Being essential and fundamental for education, educational resources are the most important for facilitating advancement of education too. Hence, efforts must be made to vigorously promote development of educational resources, especially high-quality educational resources by information technologies. With social advantages and limitations in each era, educational system and mechanism are bound to be progressively improved by independent reform, or eliminated by external revolutions with the progress of society. Nonetheless, it is undeniable that sufficient educational resources are fundamental for the educational system and mechanism no matter they are improved or eliminated. From this perspective, it is fairly necessary to develop "national exquisite courses" and "national exquisite open courses" launched by the Ministry of Education in recent years.

Although it is important to develop educational resources, it is more critical to properly allocate limited resources to reflect educational equality to the largest extent. To solve the problem regarding uneven allocation of educational resources, it is necessary to attach great importance to resource sharing and dissemination means. If educational resources aren't spread and shared, their existence will be meaningless no matter how excellent they are. Knowledge won't be valuable unless it is constantly disseminated. Both high-quality educational resources and adequate dissemination channels are indispensable, so only if they are integrated can problems about insufficient resources and unequal distribution be solved to promote progress of education.

There are necessities for sharing and spreading high-quality educational resources. As long as they are spread at faster speed, they will be disseminated more extensively and create more potential benefits. It is practical and feasible to solve problems on equality of Chinese education by widely spreading and circulating high-quality educational resources. 
Internet is a major way for disseminating high-quality educational resources. However, children of some areas possibly have never accessed internet, since the development is extremely unbalanced in different areas of China. In light of these learners, lessons may be drawn from MIT's previous practice of publicizing OCW Program. To be exact, servers with high-quality educational resources can be deployed in local areas, and computers can be purchased by government or charitable organizations. Meanwhile, local area network can be constructed, so that aforementioned learners can obtain high-quality educational resources by that method, in order to actually change their fates through education.

\section{Dealing with Challenges to National Education Sovereignty Based on MOOC}

What on earth will MOOC change Chinese education to be urgently transformed? On 7th May 2015, it was declared by the Tsinghua University that the first Chinese degree program based on blended education known as Master Program for "Data Science and Engineering" was formally initiated. With the initiation of this program, breakthroughs were achieved in admission and training models for traditional professional Master's degree. To enroll students, learning of online courses substituted for professional examinations in that program, while interviews focused on evaluating students' creativity and practical skills. As regards cultivation, flipped classrooms based on learning of online courses were adopted. The explorations of Tsinghua University aren't only more helpful for answering the question on how to implement satisfactory education for people, but also have had the MOOC-based construction of high-quality universities or leagues of merged universities put on agenda, so as to prepare for winning in wars defending national education sovereignty.

In November 2012, the Eighteenth National Congress of the Communist Party of China was smoothly convened. On this congress, an ambitious goal of "striving to implement satisfactory education for people" was proposed. After the 18th National Congress of the Communist Party of China, the Ministry of Education carried out a range of reforms under the leadership of the State Council, including facilitating the development of modern vocational education and transforming university admission system. 2012 was just called the year of MOOC. In the 21st century, a war of education without smoke and flame would break out. This war will inevitably and tremendously influence the development of modern people's and younger generations' world outlooks, outlooks on life and values. It will concern long-term security and stability of a country and its regimes.

National education sovereignty can't be infringed, so it is necessary for people to grasp initiatives in their battlefield. The objective of "striving to implement satisfactory education for people" was put forward in the report on the 18th National Congress. This objective implies that people are generally unsatisfied with current education. In essence, the greatest challenge to present Chinese education possibly still resides in lack and uneven allocation of educational resources, particularly relevant high-quality resources.

From above analysis on development, dissemination means and speed of educational resources, it may be discovered that MOOC has just emerged at the right time. Ideal social environment and adequate technical conditions have been provided for emergence and development of MOOC. Concerning whether people accept MOOC in terms of their thoughts and ideas or not, these courses will be naturally recognized as time passes by. MOOC may not only make superior high-quality educational resources available, but also contribute to more extensive and faster flow of the resources, in order to increase resource gains.

Thus, it is evident that, on one hand, development of high-quality educational resources may be constantly strengthened by MOOC; on the other hand, extensive and rapid dissemination of high-quality educational resources may be facilitated via MOOC.

Once there are relatively adequate high-quality educational resources and systems for MOOC, government shall offer necessary supporting policies and measures to encourage the construction of MOOC-based network universities. By building such universities, reforms of educational system and mechanism will be promoted to urge various universities at all levels and teachers to transform their educational concepts, education and teaching methods for the final purpose of completely improving talent cultivation, all people's awareness of study and learning skills. 
As MOOC-based network universities become totally prevalent, global learners will be able to acquire knowledge of the world's best universities as long as internet is accessible. Furthermore, they will be able to gain credits, degrees and certificates from these best universities. Learners will be greatly inspired by these and become really interested in learning. In fact, this is just a proper model for cultivating talents.

\section{Summary}

Sooner or later, MOOC will inevitably transform conventional education. What needs to be done at present is to immediately take active actions to strive for initiatives in the battlefield defending national education sovereignty. Without education sovereignty, a country will be definitely reduced to an ideological colony of powerful countries in education, and its national sovereignty will be in jeopardy.

Massive Online Open Courses have blown their funky horns to strive for national education sovereignty. With plans and preparations in place, it will be unlikely to suffer devastating defeat, and even likely to succeed. In contrast, there will be a high likelihood of an overwhelming defeat and complete failure in case of confusion, no plans or preparations.

\section{References}

[1] G. Christensen, A. Steinmetz, B. Alcorn, A. Bennett, D. Woods, E. J. Emanuel, The mooc phenomenon: who takes massive open online courses and why?. Ssrn Electronic Journal. (2013)

[2] P. J. Guo, J. Kim, R. Rubin, How video production affects student engagement: an empirical study of MOOC videos. ACM Conference on Learning@ Scale Conference, Atlanta, 2014, pp.13.

[3] L. Breslow, D. E. Pritchard, J. Deboer, G. S. Stump, A. D. Ho, D. T. Seaton, Studying learning in the worldwide classroom research into edx's first mooc. Research \& Practice in Assessment. 8 (2013) $13-25$.

[4] D. John, Experience and Education, The Educational Forum. (1986) 241-252. 